\title{
RISK FACTORS FOR EARIY HOSPITAL READMISSION FOLLOWING TOTAL KNEE ARTHROPLASTY
}

\section{FATORES DE RISCO DE REINTERNAÇÃO HOSPITALAR PRECOCE APÓS ARTROPLASTIA TOTAL DO JOELHO}

\author{
Eva J. Lehtonen, ${ }^{1}$ Matthew C. Hess, ${ }^{1}$ Gerald McGwin JR. ${ }^{2}$ Ashish Shah, ${ }^{1}$ Alexandre Leme Godoy-Santos, ${ }^{3}$ Sameer Naranje ${ }^{1}$ \\ 1. University of Alabama at Birmingham, Department of Orthopedic Surgery, Birmingham, AL, United States. \\ 2. University of Alabama at Birmingham, Department of Public Health, Birmingham, AL, United States. \\ 3. Hospital da Clinicas HCFMUSP, Faculdade de Medicina, Universidade de Sao Paulo, Sao Paulo, SP, Brasil.
}

\section{ABSTRACT}

Objective: To identify independent risk factors, complications and early hospital readmission following total knee arthroplasty. Methods: Using the ACS-NSQIP database, we identified patients who underwent primary TKA from 2012-2015. The primary outcome was early hospital readmission. Patient demographics, preoperative comorbidities, laboratory data, operative characteristics, and postoperative complications were compared between readmitted and non-readmitted patients. Logistic regression identified independent risk factors for 30-day readmission. Results: 137,209 patients underwent TKA; 3.4\% were readmitted within 30 days. Advanced age, male sex, black ethnicity, morbid obesity, presence of preoperative comorbidities, high ASA classification, and increased operative time were independently related risk factors. Asian and no reported race were negative risk factors. Postoperative complications: acute myocardial infarction, acute renal failure, stroke, pneumonia, pulmonary embolism, and deep vein thrombosis show positive associations. Conclusions: Advanced age, male sex, black ethnicity, morbid obesity, presence of comorbidities, high ASA classification and long operative time are independent risk factors for postoperative complications and early hospital readmission following total knee arthroplasty. Level of Evidence III, Case control study.

Keywords: Arthroplasty. Knee. Patient readmission. Risk factors.

\section{RESUMO}

Objetivo: Identificar fatores de risco independentes, complicações e reinternação precoce após artroplastia total do joelho. Métodos: A partir de banco de dados ACS-NSQIP, identificamos pacientes submetidos à ATJ primária de 2012 a 2015. O desfecho primário foi a reinternação hospitalar precoce. Dados demográficos, comorbidades pré-operatórias, dados laboratoriais, características cirúrgicas e complicações pós-operatórias foram comparadas entre os pacientes reinternados e não reinternados. A regressão logística identificou fatores de risco independentes para a reinternação em 30 dias. Resultados: Foram identificados 137.209 pacientes submetidos à ATJ, sendo que 3,4\% foram reinternados no período de 30 dias. A idade avançada, o sexo masculino, a raça negra, a obesidade mórbida, a presença de comorbidades pré-operatórias, a alta classificação ASA e o aumento do tempo cirúrgico foram fatores de risco relacionados independentemente. A raça asiática e as não relatadas foram fatores de risco negativos. As complicações pós-operatórias infarto agudo do miocárdio, insuficiência renal aguda, acidente vascular cerebral, pneumonia, embolia pulmonar e trombose venosa profunda apresentaram associações positivas. Conclusões: Idade avançada, sexo masculino, raça negra, obesidade mórbida, presença de comorbidades, classificação ASA elevada e tempo cirúrgico prolongado são fatores de risco independentes de complicações pós-operatórias e reinternação precoce após artroplastia total do joelho. Nível de evidência III, Estudo de caso de controle.

Descritores: Artroplastia. Joelho. Readmissão do paciente. Fatores de risco.

Citation: Lehtonen EJ, Hes MC, McGwin Jr. G, Shah A, Godoy-Santos AL, Naranje S. Bone tunnel enlargement with non-metallic interference screws in acl reconstruction. Acta Ortop Bras. [online]. 2018;26(5):309-13. Available from URL: http://www.scielo.br/aob.

\section{INTRODUCTION}

Total knee arthroplasty (TKA) is the most common arthroplasty in the United States. ${ }^{1}$ The elderly, obese, and those with multiple comorbidities are at increased risk of developing complications, leading to high readmission rates. ${ }^{2-4}$ With increases in these patient factors, complications and readmission rates may continue to rise in patients undergoing TKA. Preoperative comorbidities, like cardiac disease, chronic obstructive pulmonary disease (COPD), diabetes mellitus, and obesity, increase the likelihood of postoperative complications. ${ }^{3,5-7}$ Demographic factors, such as age, sex, and race, Charlson Comorbidity Index, insurance type, and hospital volume have also shown to be indicators for adverse events and readmission rates. ${ }^{6,8}$ Readmission rates after TKA are under scrutiny in the United States since the implementation of Medicare Hospital Readmission

All authors declare no potential conflict of interest related to this article.

Work conducted at the Department of Orthopedics and Traumatology of the Faculdade de Medicina da Universidade de São Paulo, São Paulo, Brazil, and by the Department of Orthopedic Surgery, University of Alabama at Birmingham, Birmingham, AL, USA.

Correspondence: Rua Dr. Ovídio Pires de Campos, 333, Cerqueira Cesar, São Paulo, SP, Brazil. 04503-010. alexandrelemegodoy@gmail.com.br 
Reduction Program and the second phase of the Patient Protection and Affordable Care Act, which took effect in 2015. Under these policies, hospitals incur financial penalties for readmission rates higher than the national average after TKA. ${ }^{9}$ It is therefore crucial to investigate the risk factors leading to readmission to decrease the Medicare burden, prevent hospitals from incurring penalties, and improve patient outcomes.

A previous study of all NSQIP-database patients undergoing TKA in 2011 showed that older age, male gender, positive cancer history, elevated blood urea nitrogen (BUN), presence of a bleeding disorder, and high American Society of Anesthesiologists (ASA) score were positive predictors of readmission. ${ }^{10}$ With increasing numbers of TKA being performed in a rapidly changing healthcare landscape, it is necessary to update and refine our understanding of factors influencing readmission. The objective of this study was to identify significant, independent risk factors for readmission following TKA using data from the 2012-2015 NSQIP database.

\section{MATERIALS AND METHODS}

This study uses de-identified data from public data sets that is not considered Human Subjects Research, and was exempt from review by the Institutional Review Board. Data was obtained from the American College of Surgeons National Surgical Quality Improvement Program (ACS-NSQIP), a large national database of information voluntarily provided by over 300 hospitals in 43 states, from small rural community hospitals to large, urban academic centers. ${ }^{11}$ ACS-NSQIP is a validated, risk-adjusted, outcome based program used to measure and improve the quality of surgical care in hospitals. ${ }^{12}$ We queried for all patients in the ACS-NSQIP database who underwent TKA between 2012 and 2015. We retrospectively selected only primary TKA with Current Procedural Terminology (CPT) code 27447. We excluded uni-compartmental knee arthroplasty and total knee arthroplasty with patellofemoral arthroplasty. All variables considered in this study were used as mentioned by the NSQIP User Guide, which can be referenced for detailed variable definitions. ${ }^{13}$ We followed preoperative laboratory values including total white blood cell (WBC) count, hematocrit, platelets, creatinine, serum albumin, and international normalized ratio (INR). Preoperative comorbidities such as insulin-dependent diabetes mellitus, non-insulin dependent diabetes mellitus, smoking, COPD, current dialysis use, preoperative blood transfusion, open wound, corticosteroid use for chronic conditions, bleeding disorder, sepsis, and several other variables were followed and separated in each group. Operative variables including operative time (incision to dressing application), postoperative stay longer than 24 hours, and number of days from operation to discharge were included. Outcomes were followed for thirty days. All postoperative complications were stratified as medical or surgical (Table 3) by NSQIP clinical reviewers. Medical complications included pneumonia, unplanned intubation, mechanical ventilation for greater than forty-eight hours, acute renal failure, urinary tract infection, stroke or cerebrovascular accident, myocardial infarction (MI), blood transfusion, sepsis or septic shock, and cardiac arrest. Surgical complications included superficial surgical site infection, deep or incisional surgical site infection, organ or space surgical site infection, wound dehiscence, peripheral nerve injury, pulmonary embolism, graft or prosthesis failure, and deep venous thrombosis. Demographic and clinical variables were compared between readmitted and non-readmitted patients using t- and chi-square tests for continuous and categorical variables, respectively. Logistic regression was used to estimate odds ratios (OR) and 95\% confidence intervals (Cl) for the association between readmission and the previously mentioned variables. Only variables demonstrating significant unadjusted associations and without significant amounts of missing data, defined as less than $80 \%$ data completion, were included in the multivariate analysis. The laboratory variables had extensive missingness and were therefore excluded from the multivariate analysis. Septic shock, sepsis, and deep tissue and organ infection were also excluded from multivariate analysis due to extensive missing data. Due to limited data for individual medical comorbidities, all comorbidities were combined and analyzed. The presence or absence of comorbidity was reported as a single dichotomous variable.

\section{RESULTS}

A total of 137,209 patients were included in the study. The overall 30 -day readmission rate for patients after primary TKA was $3.4 \%$ $(4,668$ of 137,209 patients).

The average age for patients in this study was 66.6 years. Older age, male sex, black race, and higher BMI category were significant $(p<0.0001)$ demographic factors positively associated with readmission (Table 1 and Table 2). Asian and unreported race were significant $(p<0.0001)$ demographic factors negatively associated with readmission (Table 1 and Table 2). For the medical comorbidities, smoking, insulin-dependent vs non-insulin-dependent diabetes, dialysis use, hypertension, congestive heart failure, dyspnea, COPD, bleeding disorder, preoperative open wound and wound infection, as well as corticosteroid use were significantly $(p<0.0001)$ positively associated with readmission. Laboratory values such as elevated WBC count, low hematocrit, low platelets, elevated creatinine, low serum albumin, and elevated INR were also significantly $(p<0.0001)$ positively associated with readmission. Other operative variables, such as increased operation time, use of general anesthesia vs other techniques, and increased time from operation to discharge also demonstrated significant $(p<0.0001)$ positive associations with readmission.

All variables shown in Table 3 demonstrated statistically significant $(p<0.0001)$ positive associations with readmission. The overall complication rate among readmitted patients was 58.0\% $(6,143$ of 137,209 patients) compared to $10.4 \%$ among non-readmitted patients. Among readmitted patients, 32.4\% developed medical complications and $25.6 \%$ developed surgical complications.

Each year of increasing age (OR, per year: 1.02; 95\% Cl, 1.02 to 1.03) and black vs white race (OR, black vs white race: $1.24 ; 95 \%$ $\mathrm{Cl}, 1.11$ to 1.37) were significant independent positive risk factors for 30-day readmission. Female vs male sex (OR, female vs male: $0.78 ; 95 \% \mathrm{Cl}, 0.73$ to 0.83 ), Asian vs white race (OR, Asian vs white race: $0.62 ; 95 \% \mathrm{Cl}, 0.48$ to 0.80 ), and unknown or unreported vs white race $(\mathrm{OR}$, unreported vs white race: $0.87 ; 95 \% \mathrm{Cl}, 0.78$ to 0.96) demonstrated significant protective effects. Morbidly obese patients had significantly higher odds of readmission than overweight patients (OR: 1.20; 95\% Cl, 1.08 to 1.32). Patients with ASA class 4 had more than twice the odds of being readmitted compared to those with ASA class 2 (OR: 2.06; $95 \% \mathrm{Cl}, 1.73$ to 2.44). Patients with ASA class 3 also had significantly higher odds of readmission compared to those with ASA class 2 (OR: 1.43; $95 \% \mathrm{Cl}, 1.34$ to 1.53). Each additional minute of operative time was found to be an independent positive risk factor for readmission (OR per minute: $1.002 ; 95 \% \mathrm{Cl}, 1.002$ to 1.003 ). The presence of one or more preoperative comorbidity was positively associated with readmission compared to patients with no comorbidities (OR: $1.29 ; 95 \% \mathrm{Cl}, 1.25$ to $1.34, \mathrm{p}<0.0001$ ). (Table 2)

All postoperative complications included in the multivariate analysis demonstrated significant independent associations with readmission (Table 3). Patients who were readmitted had over ten-times the odds of postoperative pneumonia, $\mathrm{Ml}$, acute renal failure, stroke, or ventilator use for over 48 hours. Similarly, patients who were readmitted had over ten-times the odds of postoperative superficial surgical site infection, pulmonary embolism, or deep vein thrombosis. 
Table 1. Preoperative and Operative Characteristics.

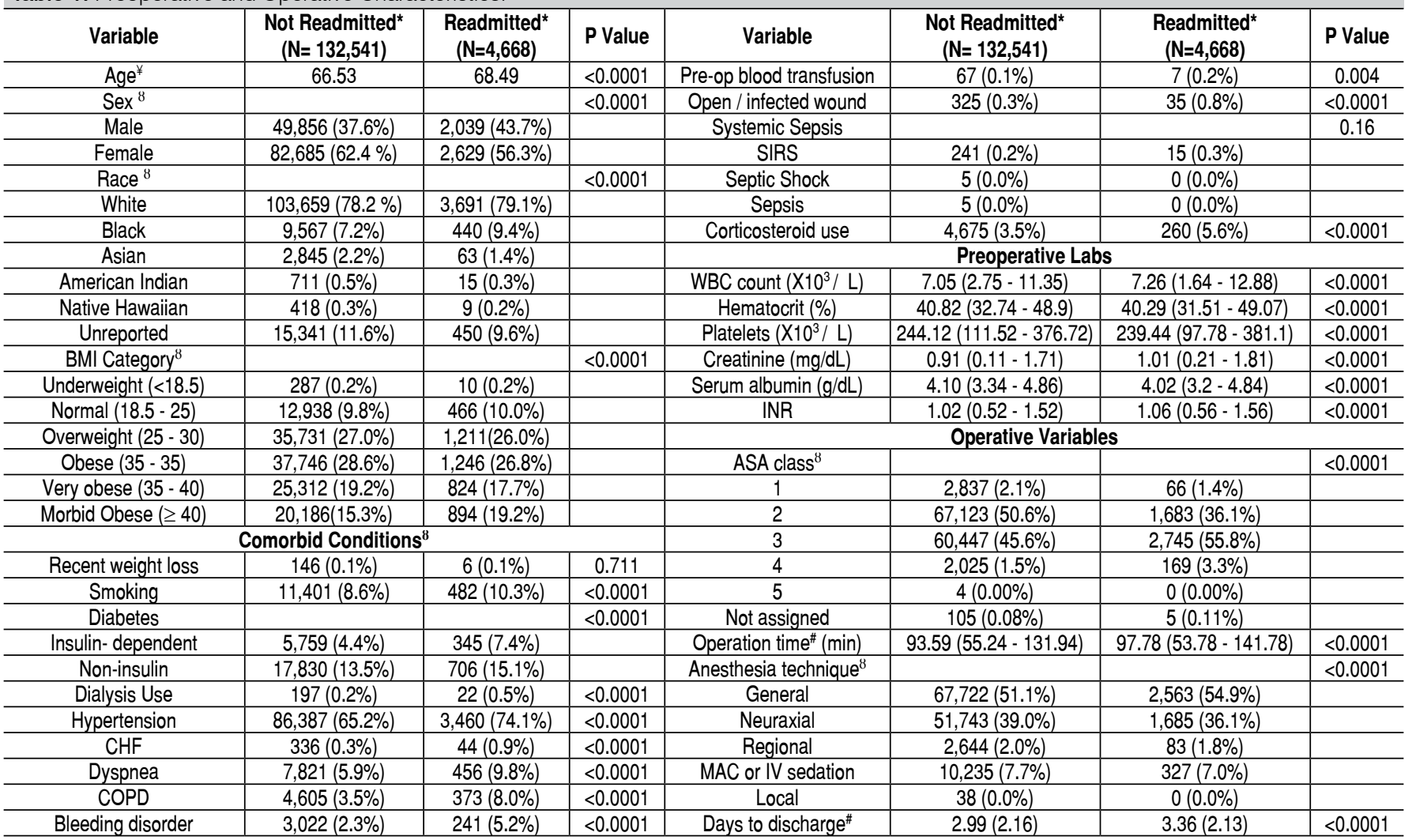

* Some data points were unrecorded and were therefore unavailable for inclusion in the evaluation. $¥$ The values given represent the average age of patients, in years. 8 The values are given as a number of patients, with the percentage in parentheses. \# The values given represent an average, with 1 standard deviation in parentheses.

Table 2. Preoperative and Operative Characteristics as Risk Factors for Readmission After Total Knee Arthroplasty

\begin{tabular}{c|c|c}
\hline Variable & Odds Ratio $(95 \%$ Cl) & P value \\
\hline Preoperative Characteristics & & \\
\hline Age (per year) & $1.021(1.018$ to 1.025$)$ & $<0.0001$ \\
\hline Sex female vs male & $0.78(0.73$ to 0.83$)$ & $<0.0001$ \\
\hline Race & & \\
\hline Black vs White & $1.24(1.11$ to 1.37$)$ & $<0.0001$ \\
\hline Asian vs White & $0.62(0.48$ to 0.80$)$ & 0.0002 \\
\hline Native Hawaiian vs White & $0.58(0.30$ to 1.13$)$ & 0.1118 \\
\hline American Indian vs White & $0.60(0.36$ to 1.00$)$ & 0.0514 \\
\hline Non reported vs White & $0.87(0.78$ to 0.96$)$ & 0.0048 \\
\hline BMI Category & & \\
\hline Underweight vs Overweight & $1.06(0.56$ to 1.99$)$ & 0.8670 \\
\hline Normal vs Overweight & $1.11(0.99$ to 1.23$)$ & 0.0750 \\
\hline Obese vs Overweight & $0.96(0.88$ to 1.04$)$ & 0.2742 \\
\hline Very obese vs Overweight & $0.92(0.84$ to 1.01$)$ & 0.0715 \\
\hline Morbidly Obese vs Overweight & $1.20(1.08$ to 1.32$)$ & 0.0003 \\
\hline Comorbidities & $1.29(1.25$ to 1.34$)$ & $<0.0001$ \\
\hline Operative variables & & \\
\hline ASA class & & \\
\hline 1- No disturb vs 2 -Mild Disturb & $1.19(0.93$ to 1.53$)$ & 0.1705 \\
\hline 3- Severe Disturb vs 2 -Mild Disturb & $1.43(1.34$ to 1.53$)$ & $<0.0001$ \\
\hline 4- Life Threat vs 2 -Mild Disturb & $2.06(1.73$ to 2.44$)$ & $<0.0001$ \\
\hline Non Assigned vs 2 -Mild Disturb & $1.75(0.71$ to 4.32$)$ & 0.2225 \\
\hline Operation time (per min) & $1.002(1.002$ to 1.003$)$ & $<0.0001$ \\
\hline
\end{tabular}

$¥$ The values are given as the odds ratio, with the $95 \% \mathrm{Cl}$ in parentheses. ₹ Logistic regression modeling adjusted for age, sex, race, BMl category, and presence of one of more preoperative comorbidities, ASA class, and operative time.

\section{DISCUSSION}

The number of TKA being performed across the U.S is increasing, presenting a challenge in a rapidly changing healthcare landscape. Changing patient demographics and regulations creating financial penalties for adverse patient outcomes has created an incentive for scrutiny in this area. A previous study of the ACS-NSQIP database from 2011 found that older age, male gender, positive cancer history, elevated BUN, presence of a bleeding disorder, and high ASA score were shown to be positive predictors of readmission, though, this focused on all joint arthroplasties. ${ }^{10}$ However, with TKA being the most common performed arthroplasty along with the availability of multiple years of additional data, it is necessary to update and refine our understanding of factors influencing readmission following TKA. Our analysis of the data from a cohort of 137,209 patients from 2012-2015 found that the 30-day readmission rate following TKA was $3.4 \%$. Many demographic characteristics, preoperative comorbidities, laboratory abnormalities and postoperative complications were associated with higher rates of readmission following TKA. Increasing age, male sex, black race, morbid obesity, presence of one or more comorbidities, postoperative complications, ASA class 3 or 4 , and longer operation time demonstrated significant, independent positive associations with 30-day readmission following TKA.

Our study's 30 -day readmission rate $(3.4 \%)$ is consistent with existing literature; 30-day readmission rates following TKA have been reported between $2.4 \%-5.8 \% .^{10,14-18}$ Our study reports a lower 30-day readmission rate compared with Pugely et al's 2011 study of the same NSQIP database (3.4\% vs $4.6 \%),{ }^{10}$ which may suggest that regulatory efforts and risk reduction initiatives in recent years have had a positive effect. This is consistent with an institutional cohort by Keeney et al which showed that introduction of risk reducing initiatives significantly reduced 30 -day readmission rates following 
Table 3. Postoperative complications as risk factors for readmission after total knee arthroplasty.

\begin{tabular}{|c|c|c|c|c|c|}
\hline & Not Readmitted $^{\star 8}(\mathrm{~N}=132,541)$ & Readmitted $^{* 8}(\mathrm{~N}=4,668)$ & P Value ${ }^{\pi}$ & Odds Ratio $(95 \% \mathrm{Cl})^{¥ \neq}$ & P Value $^{\ddagger}$ \\
\hline Overall complications & $13,835(10.4 \%)$ & $6,143(58.0 \%)$ & $<0.0001$ & & \\
\hline Medical complications & $11,753(8.9 \%)$ & $1,513(32.4 \%)$ & $<0.0001$ & & \\
\hline Pneumonia & $327(0.3 \%)$ & $176(3.8 \%)$ & $<0.0001$ & $12.15(10.04$ to 14.71$)$ & $<0.0001$ \\
\hline Unplanned intubation & $138(0.1 \%)$ & $66(1.4 \%)$ & $<0.0001$ & $9.94(7.35$ to 13.46$)$ & $<0.0001$ \\
\hline Urinary tract infection & $975(0.7 \%)$ & $225(4.8 \%)$ & $<0.0001$ & $6.22(5.34$ to 7.23$)$ & $<.0 .0001$ \\
\hline Ventilator for more than 48 hours & $62(0.1 \%)$ & $35(0.8 \%)$ & $<0.0001$ & 11.16 (7.28 to 17.09$)$ & $<.0 .0001$ \\
\hline Stroke or cerebrovascular accident & $72(0.1 \%)$ & $37(0.8 \%)$ & $<0.0001$ & $12.18(8.11$ to 18.28$)$ & $<.0 .0001$ \\
\hline Acute renal failure & $41(0.0 \%)$ & $33(0.7 \%)$ & $<0.0001$ & 15.26 (9.50 to 24.52$)$ & $<.0 .0001$ \\
\hline Cardiac arrest & $81(0.1 \%)$ & $30(0.6 \%)$ & $<0.0001$ & 7.68 (5.00 to 11.81$)$ & $<.0 .0001$ \\
\hline Septic Shock & $32(0.0 \%)$ & $57(1.2 \%)$ & $<0.0001$ & & \\
\hline Sepsis & $67(0.1 \%)$ & $191(4.1 \%)$ & $<0.0001$ & & \\
\hline Myocardial infarction (MI) & $152(0.1 \%)$ & $125(2.7 \%)$ & $<0.0001$ & $18.48(14.47$ to 23.58$)$ & $<.0 .0001$ \\
\hline Blood transfusion & $9,806(7.4 \%)$ & $538(11.5 \%)$ & $<0.0001$ & $1.41(1.28$ to 1.55$)$ & $<.0 .0001$ \\
\hline Surgical complications & $2,082(1.6 \%)$ & $1,195(25.6 \%)$ & $<0.0001$ & & \\
\hline Superficial surgical site infection & $481(0.4 \%)$ & $224(4.8 \%)$ & $<0.0001$ & $13.53(11.46$ to 15.98$)$ & $<.0 .0001$ \\
\hline Deep or incisional surgical site infection & $49(0.0 \%)$ & $164(3.5 \%)$ & $<0.0001$ & & \\
\hline Organ or space surgical site infections & $26(0.0 \%)$ & $179(3.8 \%)$ & $<0.0001$ & & \\
\hline Pulmonary embolism & $613(0.5 \%)$ & $319(6.8 \%)$ & $<0.0001$ & $16.45(14.27$ to 18.96$)$ & $<.0 .0001$ \\
\hline Deep venous thrombosis & $913(0.7 \%)$ & $309(6.6 \%)$ & $<0.0001$ & $10.32(9.02$ to 11.82$)$ & $<.0 .0001$ \\
\hline
\end{tabular}

* Some data points were unrecorded and were therefore unavailable for inclusion in the evaluation. 8 The value are given as a number of patients, with the percentage in parentheses. $\uparrow \mathrm{P}$ value from univariate modeling. $¥$ The values are given as the odds ratio, with the $95 \% \mathrm{Cl}$ in parentheses. $\neq$ Logistic regression modeling adjusted for age, sex, race, and presence of one of more preoperative comorbidities, ASA class, and operative time. Not adjusted for concurrent medical or surgical complications.

TKA at their institution from $5.6 \%$ in $2006-2009$ to $3.0 \%$ in $2010-2013$ $(p<0.001) .{ }^{17}$ However, it is also possible that our large sample size was responsible for the differences between our results and the previous study by Pugely et al.

Our findings that increasing age, male sex, comorbidities, high BUN and high ASA score are associated with higher rates of readmission are consistent with other studies, ${ }^{10,18}$ although large amounts of missing data points prevented us from identifying BUN as a predictor on multivariate analysis. We identified additional variables as risk factors for 30-day readmission that were not found by Pugely et al, including black versus white race, operative time, morbid obesity, and medical and surgical postoperative complications. D'Apuzzo, et al's 2017 study of 377,705 patients from the Statewide Planning and Research Cooperative System (SPARCS) database reported that black race was associated with increased TKA-specific 30-day readmissions, but not all-cause readmissions, as was the case in our study. Similar to our study D'Apuzzo found that Asian race was significantly negatively associated with all cause 30-day readmission (OR: $0.65 ; 95 \% \mathrm{Cl}, 0.56$ to $0.75 ; \mathrm{p}<0.001) .{ }^{18}$ However, unreported race was significantly negatively associated with readmissions compared to white race (OR: $0.87,95 \% \mathrm{Cl}, 0.78$ to 0.96 ) in our study, whereas D'Apuzzo reported a significant positive association (OR: $1.62 ; 95 \% \mathrm{Cl}, 1.52$ to 1.71$){ }^{18}$

Readmission rate was higher among morbidly obese patients (4.24\%, 894 of 21,080 patients) compared to all other BMI categories, and morbid obesity was associated with higher odds of readmission (OR: 1.20; 95\%Cl, 1.08 to 1.32). Neither Pugely or D'Apuzzo reported that BMI over $35 \mathrm{~kg} / \mathrm{m}^{2}$ or obesity, respectively, were risk factors for all-cause readmission in TKA, though D'Apuzzo did report a positive association between obesity and TKA-specific readmission. ${ }^{10,18}$ In this study, $58 \%$ of readmitted patients experienced medical or surgical complications in the postoperative period compared to $10.4 \%$ of non-readmitted patients, and multiple medical and surgical complications were positively associated with increased odds of readmission. D'Apuzzo et al also found medical and surgical in-hospital complications to be associated with increased odds of 30-day readmission, although they did not stratify by individual complication type. In our study the largest positive association with readmission among postoperative complications was MI. Readmitted patients had more than 18 times higher odds of experiencing $\mathrm{Ml}$ than non-readmitted patients. Thus improvements in preventing $\mathrm{Ml}$ or identifying patients most at risk of developing
$\mathrm{MI}$ prior to surgery may help decrease readmission. Acute renal failure (Odds Ratio 15.26) and other pulmonary complications (ventilator use, pneumonia, and unplanned intubation) were close behind $\mathrm{Ml}$ as high magnitude positive risk factors of readmission. While a cardiopulmonary exam and basic renal function panel are staples of the preoperative assessment, our results emphasize the importance of thorough preoperative workup when attempting to reduce hospital readmissions. Many surgeons require a note from the primary care provider before a total knee replacement or that patients demonstrate a certain level of cardiopulmonary fitness prior to surgery. Standardized preoperative assessments and further identification of patients at risk of developing these complications may help reduce readmission after TKA. Postoperative deep venous thrombosis and pulmonary embolism were also high magnitude independent risk factors for readmission (Odds Ratio 16.45 and 10.32 , respectively). While the majority of institutions and physicians implement prophylactic pharmacologic anticoagulation in the postoperative period, our findings emphasize the importance of patient education and preventive care to decrease hospital readmissions within 30 days of surgery.

Aside from medical and surgical complications, very high ASA class was associated with the highest odds of readmission. Patients with ASA class 4 had more than twice the odds of readmission compared to ASA class 2. Similarly, patients with ASA class 3 had 1.43 times the odds of readmission than ASA class 2 patients. Multiple retrospective studies of individual institutions report similar findings. ${ }^{16,19}$ The ASA classification system is widely utilized and available as a reliable predictor of readmission risk after TKA.

Better understanding of risk factors allows the development and implementation of evidence-based interventions aimed at mitigating risks and reducing 30-day readmission rates following TKA. These risk factors for readmission are already being utilized to reduce hospital costs; young patients with low ASA scores and few medical comorbidities are often discharged early (0-2 days) and these early discharges are not associated with increased complications or readmissions. ${ }^{20}$

Information from this study can be used to identify and counsel high-risk patients prior to surgery. Continued research and understanding in this area will allow more informed discussion of each patient's individual risks and benefits for undergoing TKA. We hope this information will be used by healthcare providers to improve 
the anticipation, prevention, and early detection of poor outcomes, leading to reduced cost and improved patient care.

The results of this study should be interpreted in light of certain limitations. Demographically our patient sample was majority female $(62.2 \%)$ and racially non-diverse. The overwhelming majority of patients were white $(78.2 \%)$ or unreported $(11.5 \%)$. Although we used a widely studied, validated database, errors in data entry or misclassifications may have occurred. This may be particularly important in calculated variables, such as BMI, which relies on the accuracy of both height and weight. This study was also limited by significant amounts of missing data in certain variables of interest.

\section{CONCLUSION}

This study was successful in identifying new variables associated with early readmission in patients undergoing TKA. Increasing age, male sex, black race, morbid obesity, the presence of preoperative comorbidities, high ASA class and increased operative time were significant positively associated independent risk factors rates following TKA.

\section{ACKNOWLEDGEMENTS}

Sawyer Muller, B.Sc.; Davis Stibolt, B.Sc.; Kevin Shrestha, B.Sc.; Martim Pinto, M.D. from Department of Surgery, Division of Orthopaedic Surgery, University of Alabama, Birmingham, AL, USA

AUTHORS' CONTRIBUTIONS: Each author made significant individual contributions to this manuscript. EJIL (0000-0003-2844-5688)*: wrote and reviewed the article; HAP (0000-0001-8456-461X)*: contributed to the acquisition of data; MCH (0000-0003-0435-5215)*: wrote and reviewed the article; GM (00000001-9592-1133)*: obtained the data and performed statistical analysis; AS (0000-0001-5806-9498)*: contributed to the interpretation of data and critical review; ALGS (0000-0002-6672-1869)*: critical review; SN (0000-0003-0538-4528)*: reviewed the article, performed statistical analysis and contributed to the intellectual concept of the study and the entire research project. *ORCID (Open Researcher and Contributor ID).

\section{REFERENCES}

1. Maradit Kremers H, Larson DR, Crowson CS, Kremers WK, Washington RE, Steiner CA, et al. Prevalence of Total Hip and Knee Replacement in the United States. J Bone Joint Surg Am. 2015;97(17):1386-97.

2. Martin JR, Jennings JM, Dennis DA. Morbid Obesity and Total Knee Arthroplasty: A Growing Problem. J Am Acad Orthop Surg. 2017;25(3):188-94.

3. Schwarzkopf R, Thompson SL, Adwar SJ, Liublinska V, Slover JD. Postoperative complication rates in the "super-obese" hip and knee arthroplasty population. J Arthroplasty. 2012;27(3):397-401.

4. Vorhies JS, Wang Y, Herndon JH, Maloney WJ, Huddleston JI. Decreased length of stay after TKA is not associated with increased readmission rates in a national Medicare sample. Clin Orthop Relat Res. 2012;470(1):166-71.

5. Lopez-de-Andres A, Hernandez-Barrera V, Martinez-Huedo MA, Villanueva-Martinez M, Jimenez-Trujillo I, Jimenez-Garcia R. Type 2 diabetes and in-hospital complications after revision of total hip and knee arthroplasty. PloS one. 2017;12(8):e0183796.

6. Higuera CA, Elsharkawy K, Klika AK, Brocone M, Barsoum WK. 2010 Mid-America Orthopaedic Association Physician in Training Award: predictors of early adverse outcomes after knee and hip arthroplasty in geriatric patients. Clin Orthop Relat Res. 2011;469(5):1391-400.

7. Weaver F, Hynes D, Hopkinson W, Wixson R, Khuri S, Daley J, et al. Preoperative risks and outcomes of hip and knee arthroplasty in the Veterans Health Administration. J Arthroplasty. 2003;18(6):693-708.

8. SooHoo NF, Lieberman JR, Ko CY, Zingmond DS. Factors predicting complication rates following total knee replacement. J Bone Joint Surg Am. 2006;88(3):480-5

9. Hackbarth G, Reischauer R, Mutti A. Collective accountability for medical care--toward bundled Medicare payments. N Engl J Med. 2008;359(1):3-5.

10. Pugely AJ, Callaghan JJ, Martin CT, Cram P, Gao Y. Incidence of and risk factors for 30-day readmission following elective primary total joint arthroplasty: analysis from the ACS-NSQIP. J Arthroplasty. 2013;28(9):1499-504.

11. Schilling PL, Hallstrom BR, Birkmeyer JD, Carpenter JE. Prioritizing perioperative quality improvement in orthopaedic surgery. J Bone Joint Surg Am. 2010;92(9):1884-9.

12. American College of Surgeons National Surgical Quality Improvement Program. Data collection, analysis, and reporting. Chicago, IL: American College of Surgeons; [cited 2017 July]. Available from: https://www.facs.org/quality-programs/ acs-nsqip.

13. User Guide for the ACS NSQIP Participant Use Data File (PUF): American College of Surgeons National Surgical Quality Improvement Program; 2016 [cited 2017 August]. Available from: https://www.facs.org/ /media/files/qualityprograms/ nsqip/nsqip_puf_user_guide_2015.ashx.

14. Bosco JA 3rd, Karkenny AJ, Hutzler LH, Slover JD, lorio R. Cost burden of 30-day readmissions following Medicare total hip and knee arthroplasty. $J$ Arthroplasty. 2014;29(5):903-5.

15. Schairer WW, Vail TP, Bozic KJ. What are the rates and causes of hospital readmission after total knee arthroplasty? Clin Orthop Relat Res. 2014;472(1):181-7.

16. Tayne S, Merrill CA, Smith EL, Mackey WC. Predictive risk factors for 30-day readmissions following primary total joint arthroplasty and modification of patient management. J Arthroplasty. 2014;29(10):1938-42

17. Keeney JA, Nam D, Johnson SR, Nunley RM, Clohisy JC, Barrack RL. The Impact of Risk Reduction Initiatives on Readmission: THA and TKA Readmission Rates. J Arthroplasty. 2015;30(12):2057-60.

18. D'Apuzzo M, Westrich G, Hidaka C, Jung Pan T, Lyman S. All-Cause Versus Complication-Specific Readmission Following Total Knee Arthroplasty. J Bone Joint Surg Am. 2017;99(13):1093-103.

19. Schaeffer JF, Scott DJ, Godin JA, Attarian DE, Wellman SS, Mather RC 3rd. The Association of ASA Class on Total Knee and Total Hip Arthroplasty Readmission Rates in an Academic Hospital. J arthroplasty. 2015;30(5):723-7.

20. Sutton JC 3rd, Antoniou J, Epure LM, Huk OL, Zukor DJ, Bergeron SG. Hospital Discharge within 2 Days Following Total Hip or Knee Arthroplasty Does Not Increase Major-Complication and Readmission Rates. J Bone Joint Surg Am. 2016;98(17):1419-28. 